\title{
SISTEM MONITORING KANDANG BURUNG PUYUH BERBASIS INTERNET OF THINGS PADA PLATFORM NODE-RED MENGGUNAKAN METODE NAIVE BAYES
}

Aa Zezen Zenal Abidin*1, Nasrulloh Abdul Aziz Saragih ${ }^{\# 2}$

\author{
Program Studi Teknik Informatika, STMIK Subang ${ }^{* 1}$ \\ Program Studi Teknik Informatika, STMIK Subang $\# 2$ \\ E-mail: zezen2008@yahoo.com ${ }^{* 1}$, nasrullohabdulaziz5@gmail.com ${ }^{\# 2}$
}

\begin{abstract}
Abstrak
Salah satu aktivitas ternak yang popular di Indonesia adalah ternak burung puyuh. Rentannya burung puyuh mengalami kematian yang bisa menyebabakan kegagalan panen melatarbelakangi penulis melakukan moniting kandang burung puyuh. Pada penelitian ini secaraa khusus dilakukan pengembangan system pada layer aplikasi dan layer servis di system berbasis internet of thing dengan melakukan penggunaan platform Node-Red dan pembuatan basis data local menempung data dari platform. Data akan dianalisis menggunakan salah satu metode data mining berupa metode naïve bayes. Digunakan sensor LDR dan DHT11 untuk melakukan akuisisi data sushu, kelembaban dan intensitas cahaya. Jika sushu kandang melebihi atau sama dengan 34 derajat celcius, lampu dalam kandang akan mati dan jika Jika data kurang dari sama dengan 33 derajat selsius, maka system akan menyalakan lampu dalam kandang.. Selain itu digunakan juga beberapa komponen lain seperti Arduino Mega 2560, NodeMcu ESP8266, dan media jaringan computer serta cloud application berupa platform Node-Red. Dapa diimplementasikan proto type system monitoring kandang burung puyuh berbasis IoT pada platform Node-Red menggunakan metode Naïve Bayes. Terhadap Data yang diperoleh dilakukan pengujian akurasi dan diperoleh nilai akurasi 80 persen.
\end{abstract}

Kata kunci: data mining, naïve bayes, IoT, Node-Red, burung puyuh, monitoring kandang.

\begin{abstract}
Quail Livestock is one of Indonesia's most popular livestock activities. The susceptibility of quails to death that can cause crop failure is the background to the author doing quail cages monitoring. In this study the system development on the application layer and service layer on the internet-based system of things was developed specifically by using the Node-Red platform and creating a local database with platform data. Data will be analyzed using the naïve bayes method, using one of the methods of data mining. LDR and DHT11 sensors are used for the sushu, humidity and light intensity data acquisition. If the sushu in the cage exceeds or is equal to 34 degrees Celsius, the light in the cage will switch off and if the data is less than 33 degrees Celsius, the light in the cage will turn on. Additionally, many other modules are also used, such as Arduino Super 2560, NodeMcu. ESP8266, and Node-Red platformed computer network media and cloud software. The IoT proto-type monitoring system based on IoT can be implemented on the Node-Red platform using the Nä̈ve Bayes method. The accuracy of the collected data was checked and accuracy was collected at 80 per cent.
\end{abstract}

Key Word: data mining, naïve bayes, IoT, Node-Red, Quail, Ecclosure Monitoring.

\section{Pendahuluan}

Burung Puyuh merupakan salah satu jenis ternak unggas yang popular diternakkan oleh masyarakat sebagai penghasil telur dan daging. Kandang adalah tempat yang digunakan untuk memelihara hewan ternak, tempat itu dapat berupa wadah, bangunan, atau area yang sesuai dengan kebutuhan hewan ternak tersebut. Kandang yang nyaman juga merupakan tempat bagi burung puyuh untuk tumbuh dan berkembang biak dengan baik.

Cahaya, suhu, dan kelembapan merupakan faktor eksternal yang dapat memacu pertumbuhan dan mengendalikan berbagai proses biologis dalam tubuh burung puyuh. Kesulitan saat ternak puyuh salah satunya adalah membuat agar suhu kandang tetap dalam kondisi stabil dan hangat. Karena burung merupakan salah satu unggas yang rentan dengan kondisi lingkungannya. Dilihat dari tingkat kelembapan kandang maupun lingkungan sekitar kandang juga merupakan faktor dalam 
menjaga kondisi burung puyuh.Solusi alternatif untuk mengatasi permasalahan ini adalah dengan membuat suatu alat untuk mengontrol dan suhu kandang burung puyuh agar tetap dalam kondisi yang stabil. Serta mengurangi penggunaan listrik yang berlebih daripada lampu yang digunakan.

\section{Tinjauan Pustaka}

sistem kendali peternakan jarak jauh berbasis Intenet of Things (IoT) dibuat oleh[1]. Pengawasan dan pengendalian kandang unggas sangat memudahkan pemelihara untuk mengawasi dan merawat unggas miliknya dengan efektif dan efisien. Untuk sementara alat ini telah dapat memberikan pakan dan air unggas. Level pakan dan air unggas ditampilkan dengan akurat pada serial monitor. Sedangkan data air dan pakan secara rinci yang dipantau berdasarkan waktu dapat diakses dengan mudah melalui web server dan aplikasi pada smartphone.

Prototype sistem pengaturan suhu kandang ayam berbasis mikrokontroller[2]. Perancangan pengaturan suhu kandang ayam secara otomatis berjalan dengan baik karena alat dapat bekerja dan menjaga kestabilan suhu sesuai dengan batasan suhu yang telah ditentukan. prototipe sistem kendali pengaturan suhu dan kelembaban kandang ayam boiler berbasis mikrokontroler atmega328[3]. Sistem kendali pengaturan suhu dan kelembaban pada kandang ayam Boiler ini berjalan dengan otomatis dan berulang-ulang hingga sensor DHT11 mendeteksi adanya tingkat suhu yang tinggi. implementasi Internet of Things pada sistem monitoring suhu dan kontrol air pada kandang burung puyuh dengan menggunakan protokol MQTT [4]. Sistem Monitoring Suhu dan Kontrol Air pada Kandang Puyuh Petelur Berbasis Internet of Things dengan Protokol MQTT dapat mengimplementasikan komunikasi MQTT sehingga sensor dapat tehubung dengan broker secara online dengan bantuan Wi-Fi.

sistem kontrol intensitas cahaya pada kandang puyuh berbasis arduino uno [5]. Berdasarkan hasil uji coba yang telah dilakukan, maka dapat disimpulkan bahwa alat ini mampu mengontrol intensitas cahaya yang dibutuhkan pada kandang puyuh. Mampu menghemat biaya pembayaran listrik karena hidup dan matinya pencahayaan dikontrol dengan sistem penjadwalan. Berdasarkan penelitian-penelitian sebelumnya, pada penelitian ini penulis akan mengembangkan Sistem monitoring kandang burung puyuh berbasis Internet of Things dengan melakukan pengembanagan pada aspek application layer, dengan mengunakan Platform Node-red dan pada service layer berupa penamabahn storage ( basis data) serta analisis data menggunakan metode data mining berupa Naïve Bayes. Monitoring dilakukan pada tiga paremeter, yaitu suhu, kelembaban dan intensitas cahaya, menggunakan sensor LDR(Light Dependent Resistor) dan sensor suhu DHT11

Untuk klasifikasi dengan data kontinyu digunakan rumus Densitas Gauss[6][7] atau nä̈ve bayes probabilitas densitas untuk estimasi probabilitas, sebagai berikut [8]:

$$
f(x)=\frac{1}{\sqrt{2 \pi \sigma}} e^{-\frac{(x-\mu)^{2}}{2 \sigma^{2}}}
$$

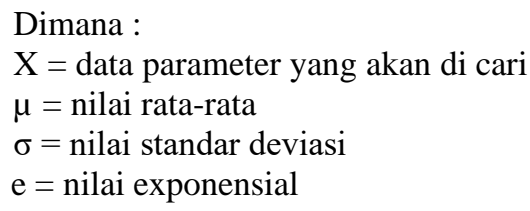

\section{Analisa dan Pembahasan}

Dilakukan pemecahan kaliamt sehingga dokumen artikel kesehatan sebagai kasus dalam penenlitian ini terbagi menjadi 13 kalimat seperti diperlihatkan dalam Tabel 1. setelah dilakukan proses tekenizing, yaitu penghilangan tanda bacaca,kemudian dilakukam proses stemming, dimana setip kalimat dipecah lagi menjadi daftar kata, dimana potongan tablenya diperlihatkan dalam Tabel 2.

Pada penelitian ini, data yang digunakan berupa data primer. Data di dapatkan dari sensor dan berdasarkan pengamatan penulis.

Data terdiri dari 3 atribut parameter dan satu atribu class, parameternya yaitu: kelembapan, suhu dan cahaya dapat dilihat pada Tabel 1. Sedangkan atribut kelasnya yaitu tingkatan suhu yang 
ditentukan berdasarkan pengamatan, data kemudian ditabulasi disesuaikan dengan kebutuhan mode Naïve Bayes sebagai data latih atau training data, untuk sementara agar mempermudah dalam pencarian nilai fungsi densitasnya data latih tersebut dibagi menjadi dua tabel berdasarkan kelasnya (data latih terlampir).

Yang mana pertama dilakukan proses mencari nilai rata-rata, dan standar devisiasi dari data tersebut.

Tabel 1 Parameter data pengontrol suhu kandang burung puyuh

\begin{tabular}{|l|l|l|}
\hline No & Atribut Paramater & Atribut Kelas \\
\hline 1 & Kelembapan & Panas \\
\hline 2 & Suhu & Normal \\
\hline 3 & Cahaya & \\
\hline
\end{tabular}

Sehingga untuk mencari nilai rata-rata, dan standar deviasi. Kemudian data yang sudah ada tersebut, selanjutnya menghitung rata-rata dan standar deviasi dari setiap class. Agar mempermudah dalam pencarian nilai fungsi densitasnya data latih tersebut dibagi menjadi dua tabel berdasarkan kelasnya

Tabel 2 Nilai rata-rata dan standar deviasi kelas panas

\begin{tabular}{|c|l|l|l|}
\hline & KELEMBAPAN & SUHU & CAHAYA \\
\cline { 2 - 4 } & PANAS & PANAS & PANAS \\
\hline MEAN & 51 & 31,6 & 152,65 \\
\hline STD.DEV & 1,55597321 & 0,50262469 & 50,56343 \\
\hline
\end{tabular}

Tabel 3 Nilai rata-rata dan standar deviasi kelas normal

\begin{tabular}{|c|c|c|c|}
\hline \multirow{2}{*}{} & KELEMBAPAN & SUHU & CAHAYA \\
\cline { 2 - 4 } & NORMAL & NORMAL & NORMAL \\
\hline MEAN & 59,76666667 & 27,8 & 289,1333 \\
\hline STD.DEV & 2,254242488 & 0,484234198 & 60,27679 \\
\hline
\end{tabular}

Tahap selanjutnya yaitu melakukan perhitungan menggunakan persamaan nä̈ve bayes probabilitas densitas untuk estimasi probabilitas:

Dimana :

$$
f(x)=\frac{1}{\sqrt{2 \pi \sigma}} e^{-\frac{(x-\mu)^{2}}{2 \sigma^{2}}}
$$

$\mathrm{X}=$ data parameter yang akan di cari

$\mu=$ nilai rata-rata

$\sigma=$ nilai standar deviasi

$\mathrm{e}=$ nilai exponensial

Tabel 4 Data parameter yang akan diuji

\begin{tabular}{|l|l|l|l|}
\hline Kelembapan & Suhu & Cahaya & Hasil Uji \\
\hline 60 & 32 & 214 & $?$ \\
\hline
\end{tabular}

Menghitung Fungsi Densitas untuk class panas

Diketahui:

$\mathrm{X} 1=60$

$\mathrm{X} 2=32$

$\mathrm{X} 3=214$

Banyak data panas $=20$

Banyak data normal $=30$

$\begin{array}{llr}\sigma & \text { kelembapan } & =1,555973212 \\ \sigma & \text { suhu } & =0,50262469 \\ \sigma & \text { cahaya } & =50,56343072\end{array}$




$\begin{array}{lll}\mu & \text { kelembapan } & =51 \\ \mu & \text { suhu } & =31,6 \\ \mu & \text { cahaya } & =152,65\end{array}$

Hitung fungsi untuk x1 (kelembapan)

$$
\begin{gathered}
f(60 \mid \text { kelembapan })=\frac{1}{\sqrt{2 \pi} \cdot 1,555973212} e^{\frac{(60-51)^{2}}{2.5 .1,555973212}} \\
f(60 \mid \text { kelembapan })=1,39288917415764 \mathrm{E}-08
\end{gathered}
$$

Hitung fungsi untuk $\mathrm{x} 2$ (suhu)

$$
\begin{gathered}
f(32 \mid \text { suhu })=\frac{1}{\sqrt{2 \pi} \cdot 0,50262469} e^{\frac{(32-31.6)^{2}}{2.0,50262469}} \\
f(34 \mid \text { suhu })=5,78281983097186 \mathrm{E}-01
\end{gathered}
$$

Hitung fungsi untuk x3 (cahaya)

$$
\begin{array}{r}
f(214 \mid \text { cahaya })=\frac{1}{\sqrt{2 \pi} \cdot 50,56343072} e^{\frac{(214-152,65)^{2}}{2.50,56343072}} \\
f(214 \mid \text { cahaya })=3,77917736022843 \mathrm{E}-03
\end{array}
$$

Menghitung Fungsi Densitas untuk class normal

Diketahui:

$\mathrm{X} 1=60$

$\mathrm{X} 2=32$

$\mathrm{X} 3=214$

Banyak data terik $=20$

Banyak data redup $=30$

$\begin{array}{lll}\sigma & \text { kelembapan } & =0,484234198 \\ \sigma & \text { suhu } & =2,254242488 \\ \sigma & \text { cahaya } & =60,27679449 \\ \mu & \text { kelembapan } & =59,76666667 \\ \mu & \text { suhu } & =27,8 \\ \mu & \text { cahaya } & =289,1333333\end{array}$

Hitung fungsi untuk x1 (kelembapan)

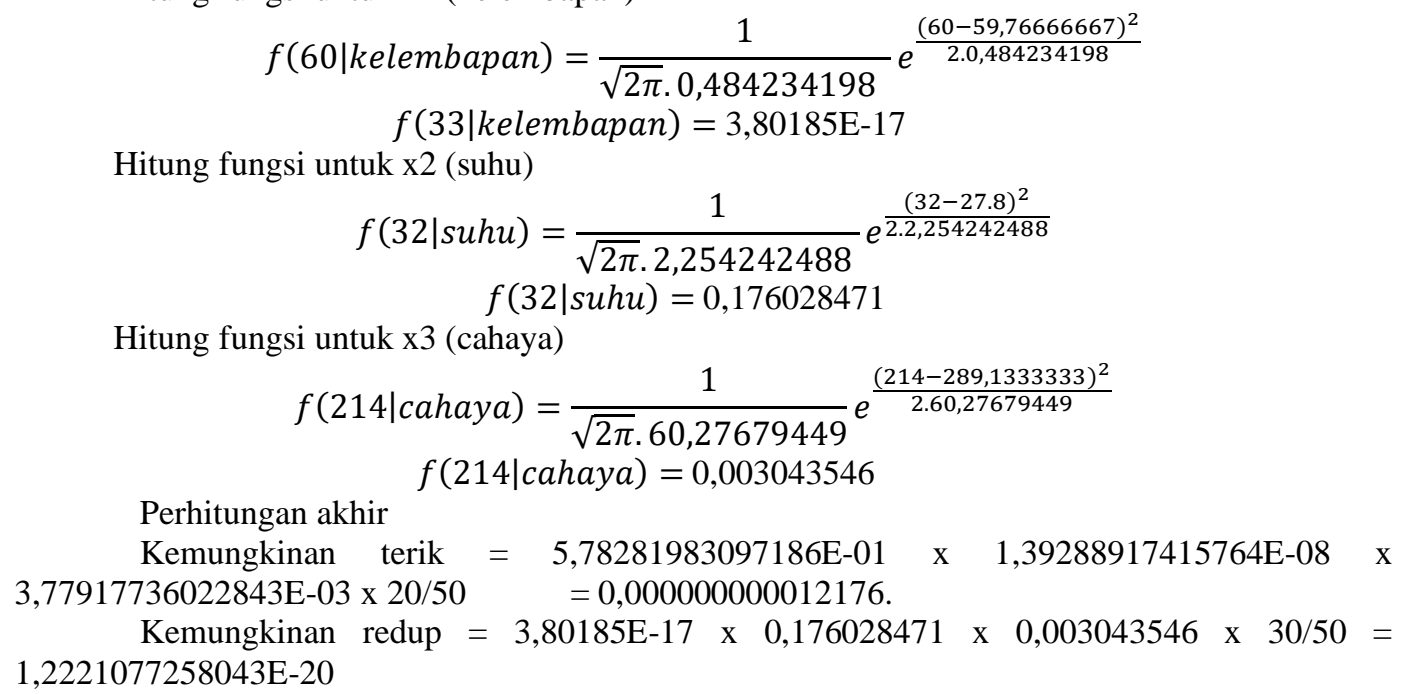


Hasil akhir perhitungan menunjukan bahwa kemungkinan NORMAL lebih besar dari pada kemungkinan PANAS.

System mulai bekerja dengan mengambil data suhu, kelembaban ruangan kandang menggunakan sensor LDR dan intensistas cahaya kandang menggunakan sensor LDR. Memlalui mikrokontroler, data akan dikirm ke platform IoT Node-Red dan ditampilkan dalam aplikasi cloud Node-Red. Data suhu, kelembaban dan intensitas cahaya dari platform akan dikirim ke dalam basis data local. Dari basis data local data akan dianalisis menggunakan metode Naïve Bayes. Jika data kurang dari sama dengan 33 derajat selsius, maka system akan menyalakan lampu dalam kandang. Jika suhu kandang lebih besar dari sama dengan 34 derajat selsius, maka lampu akan mati.

Arsitektur perangkat system monitoring kandang burung puyuh berbasis IoT pada platform node-red menggunakan metode Nä̈ve Beyes diperlihatkan dalam Gambr 1, pengembanagan dari arsitektur system[9]. System terdiri dari 5 layer, yaitu environment, sensing, network, service dan application. Hal ini dilakukan untuk mengetahui integrasi yang terdapat dalam sistem.

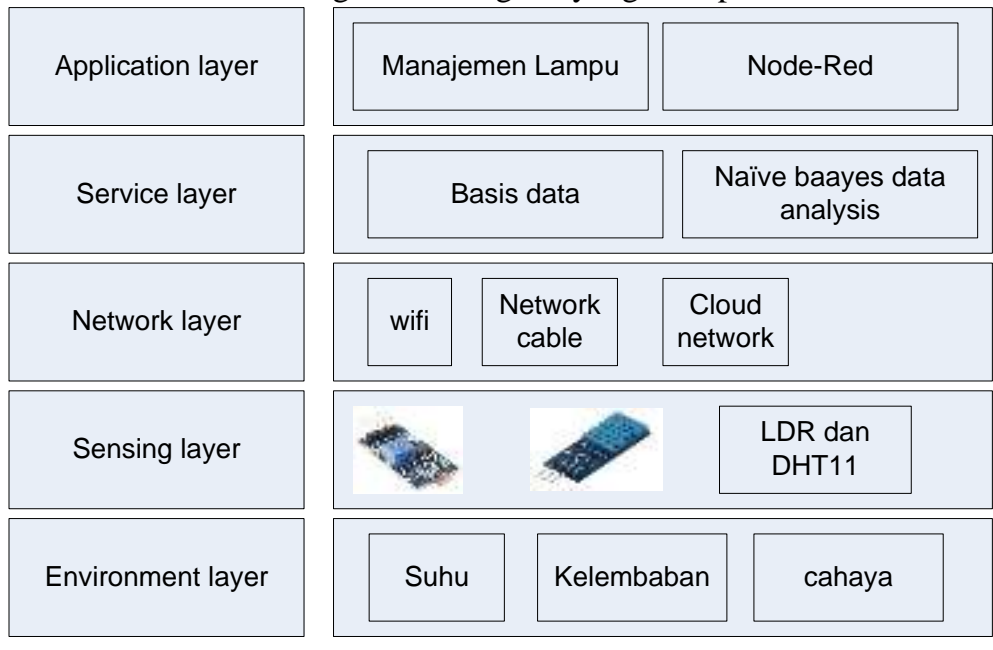

Gambar 1 Arsitektur sistem

\section{Hasil}

Untuk merealisasikan prototype system monitoring, Penulis menggunakan sebagai salah satu layer aplikasinya, penulis membuat jalur rancangan sistem dengan cara menghubungkan perintah node yang sudah disediakan, sehingga dapat terciptanya sistem sesuai yang penulis inginkan, seperti diperlihatkan dalam Gambar 2. Sedangkan tampilan luaran system dalam anatar muka Node-Red, diperlihatkan dalam Gambar 3. 


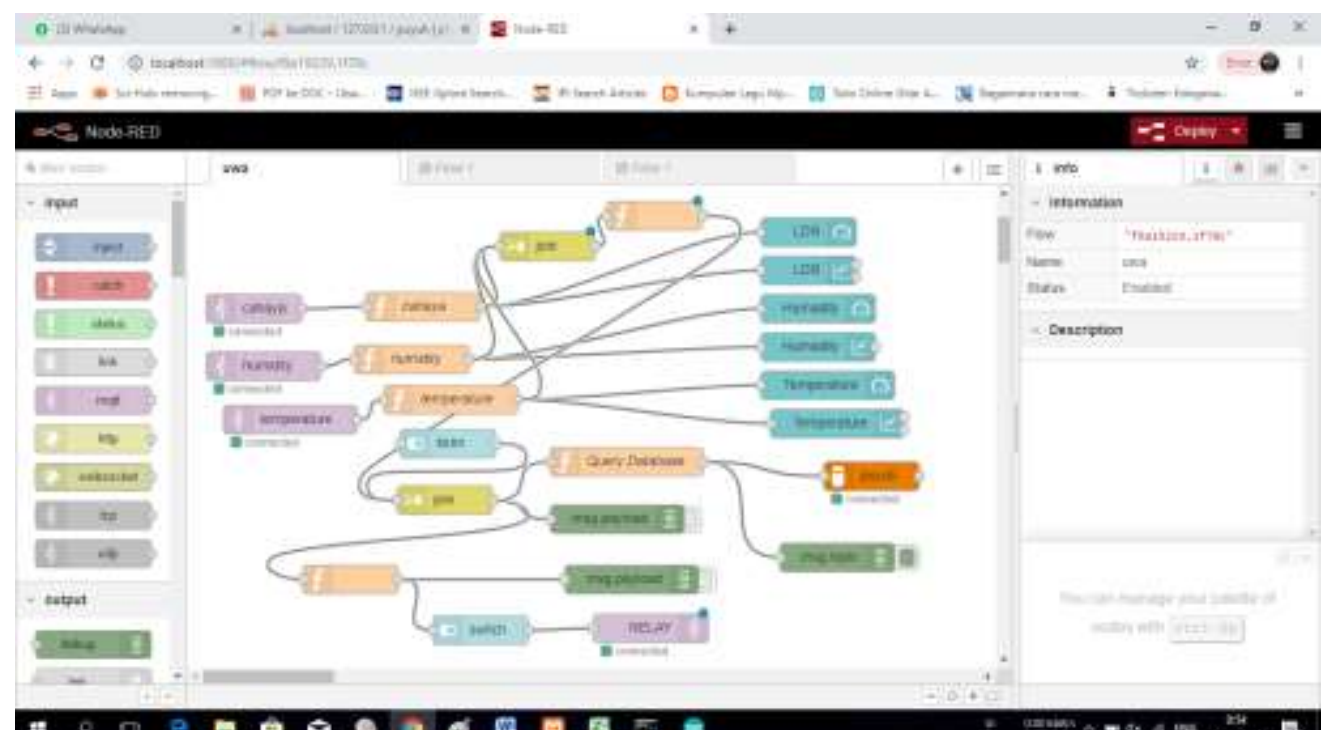

Gambar 2 Rancangan sistem menggunakan Platform node-red

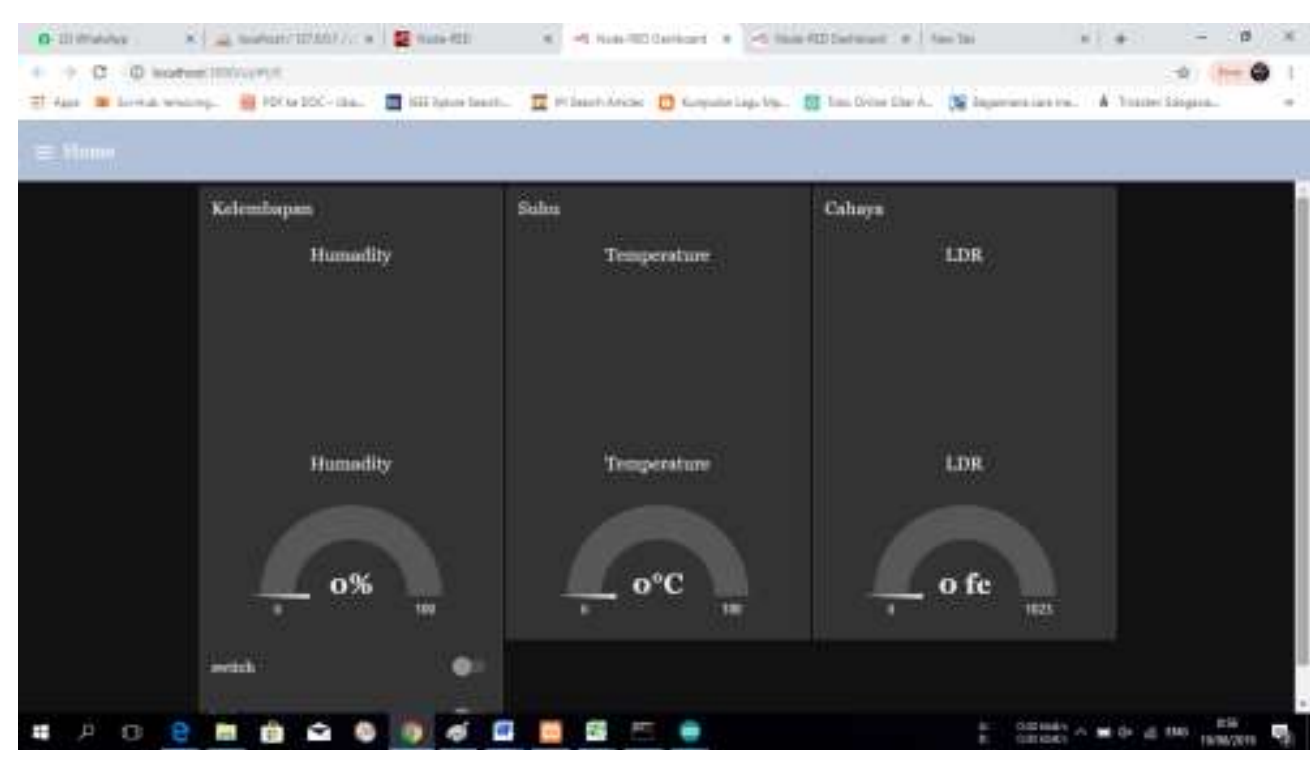

Gambar 3 Luaran system menggunakan platform node-red

Perancangan mikrokontroler merupakan proses penggabungan antara beberapa komponen, yang meliputi Arduino Mega 2560, NodeMcu ESP8266, dan modul pendukung sensor. Untuk hasil wiring (pengawatan)dapat dilihat pada Gambar 4. 


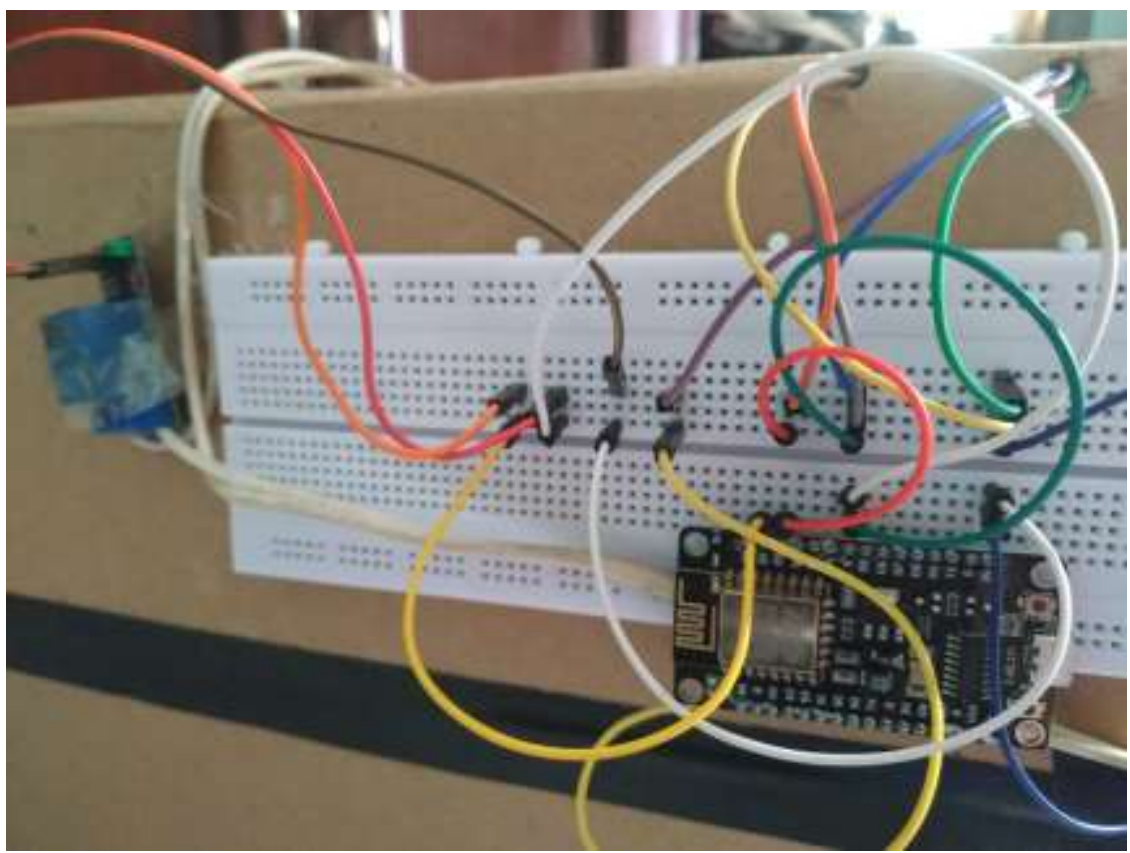

Gambar 4 Pengawatan mikrokontroler

Setelah wiring selesai, maka tahap berikutnya adalah pengujian terhadap sistem. pengujian dilakukan secara bertahap untuk lebih memudahkan evaluasi terhadap aksi yang terjadi pada perangkat sistem. Pada tahap ini akan dilakukan pengujian mikrokontroler dan sensor menggunakan serial monitor pada Aplikasi Arduino IDE. Setelah proses instalasi mikrokontroler dilakukan, selanjutnya penulis memprogram Arduino Mega 2560 dan NodeMcu ESP8266 menggunakan aplikasi Arduino IDE pada komputer. Hasil pengujian system berupa kemampuan system untuk memonitoring kanadang pada parameter suhu, kelembaban dan intensitas cahaya dapat dilihat pada Gambar 5.

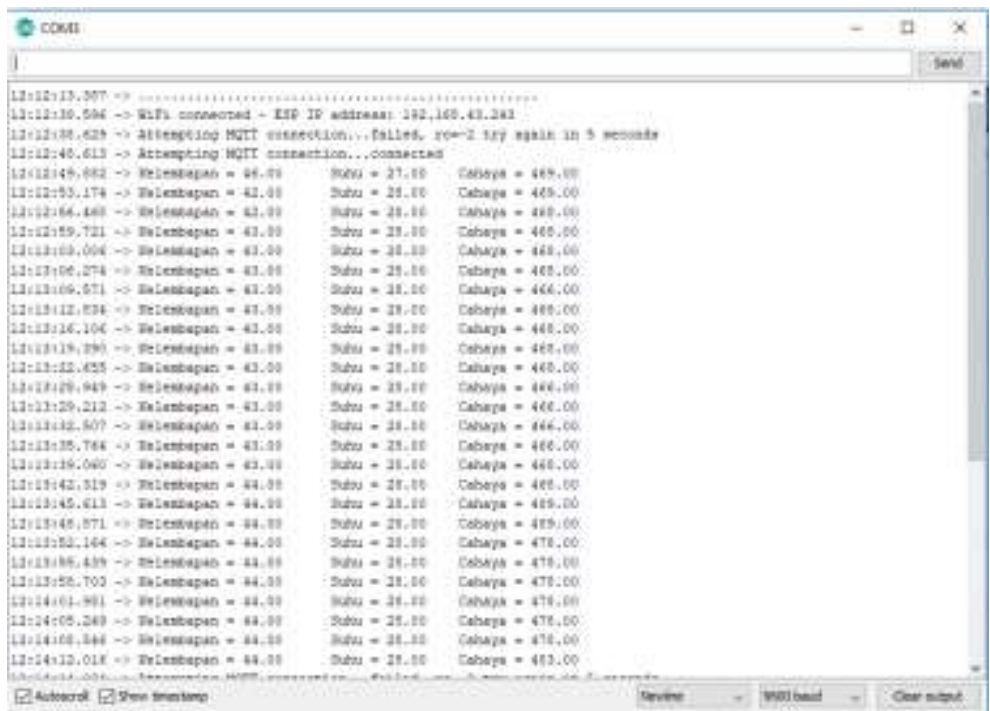

\section{Gambar 5 Pengujian mikrokontroler dan sensor menggunakan serial monitor pada aplikasi Arduino IDE}

Setelah mikrokontroler telah berfungsi dengan baik pada tahap pengujian pertama, selanjutnya penulis melakukan pengujian menggunakan platform Node-Red. Pada tahap ini, pengujian dilakaukan setelah system sudah terintegrasi seluruhnya, dipastikan perangkat komputer dan mikrokontroler sudah terhubung dalam satu jaringan, dalam pengujian ini penulis menggunakan 
akses point (wifi) sebagai media komunikasi antara komputer server dengan mikrokontroler, akses point yang digunakan adalah smartphone milik penulis yang sudah di konfigurasi.

Setelah semua proses instalasi dan konfigurasi dilakukan selanjutnya penulis melakukan pengujian terhadap alat dan sistem yang dibuat. Pengujian ini dilakukan untuk memastikan bahwa alat dan sistem yang dibuat dapat bekerja dengan baik sesuai dengan yang di inginkan. Untuk melihat hasil pengujian dapat dilihat pada Gambar 6.

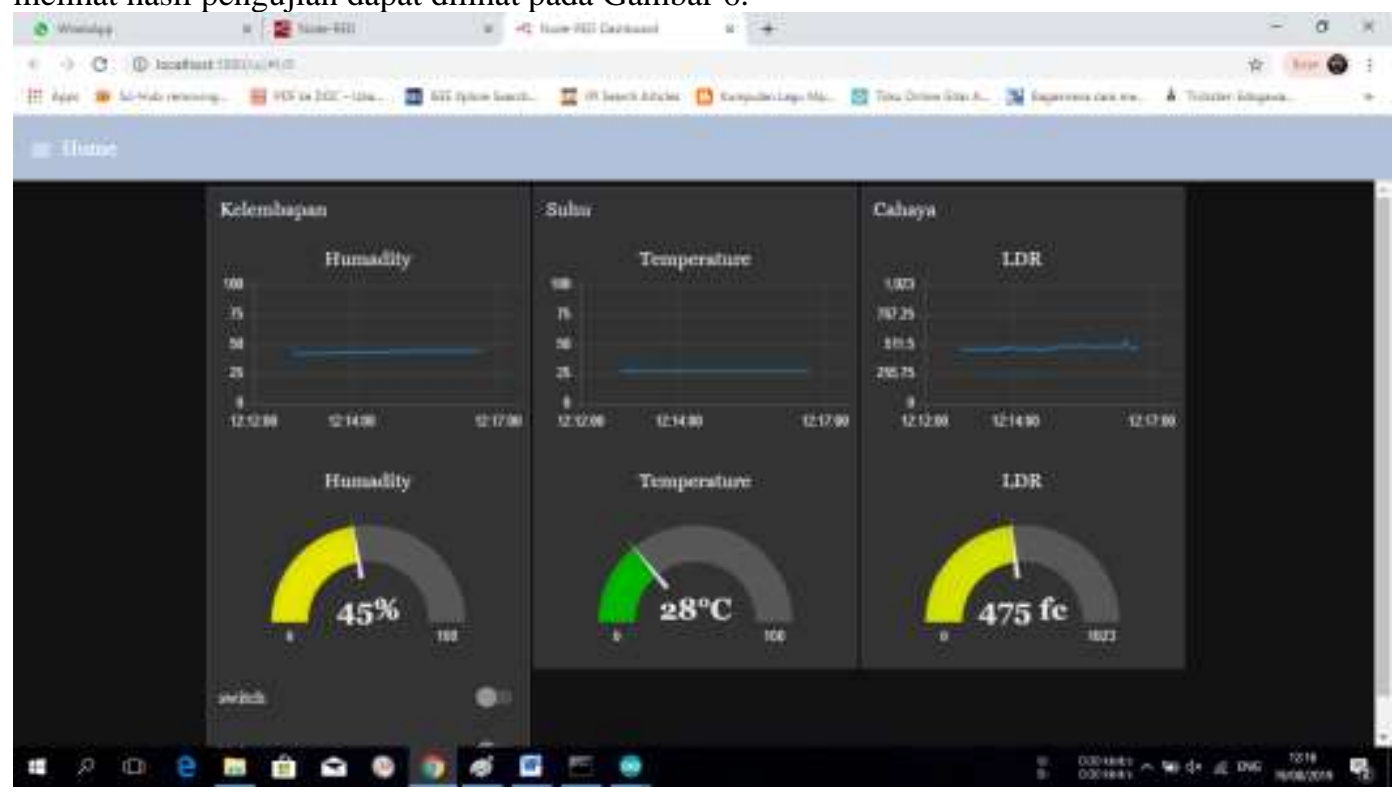

Gambar 6 Proses pengujian mikrokontroler dengan platform Node-Red

Setelah dilakukan pengujian secara bertahap terhadap sistem yang dibuat, berikutnya dilakukan pengujian secara keseluruhan. hasil pengujian rangkaian keseluruhan sistem monitoring kandang burung puyuh berbasis IoT pada platform node-red dengan menggunakan metode Naive Bayes diperlihatkan dalam Gambar 7. Dilakuakn juga analisis menggunkan tools rapidminer untuk memperoleh informasi akurasi, hasil pengujian akurasi pada rapidminer diperlihatkan dalam Gambar 8. 


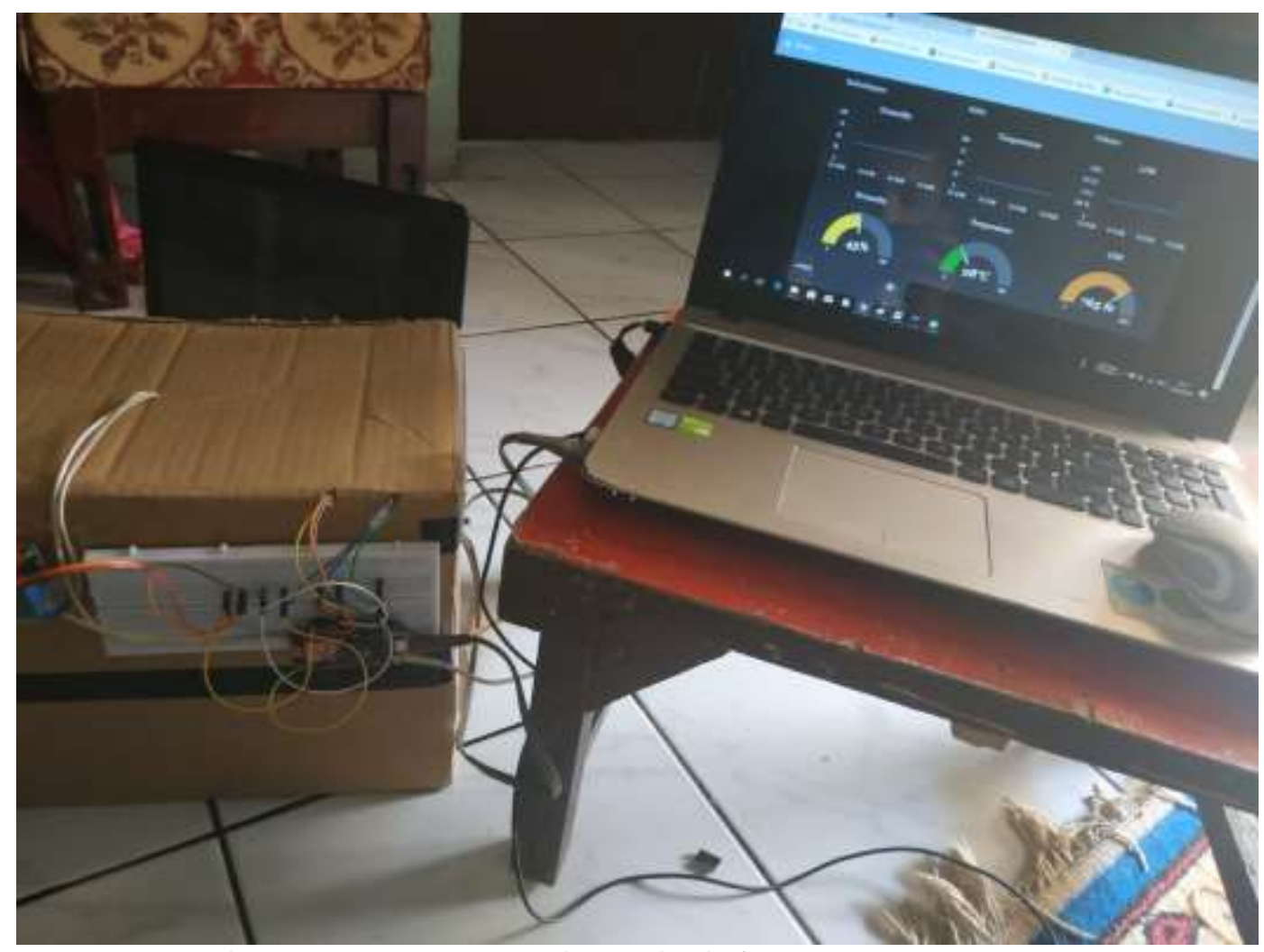

Gambar 7 Proses monitoring data pada platform Node-Red

\begin{tabular}{|c|c|c|c|}
\hline \multicolumn{4}{|c|}{ accuracyc 80.00 s. } \\
\hline & TUEPANAS & TVE NORNAK & class prectsion \\
\hline pred, PANAS & 8 & 2 & $80.00 \%$ \\
\hline pred NORMLL & 0 & 0 & $0.00 \%$ \\
\hline thase recall & $10000 \%$ & $0.00 \%$ & \\
\hline
\end{tabular}

Gambar 8 Hasil pengujian akurasi pada rapidminer 


\section{Kesimpulan}

Dapat diimplementasikan prototype system monitoring kandang burung puyuh berbasis IoT pada platform Node-Red menggunakan metode Naïve Bayes, dari hasil pengujian akurasi diperoleh nilai akurasi 80 persen. Dapat direalisasikan pengembangan system IoT pada layer apliaksi dan service dengan menggunakan antar muka aplikasi Node-Red yang interaktif dan real time serta analisi data menggunakan salah satu metode data mining berupa Naïve bayes yang diperoleh dari basis data lokal.

\section{Daftar Pustaka}

[1] Muta'affif, M. Farish, M. Mujtahid, B. El Bari, M. Evita, and M. Djamal, "Sistem Kendali Peternakan Jarak Jauh Berbasis Internet of Things ( IoT )," Pros. SKF 2017, pp. 98-102, 2017.

[2] R. K. Sebayang, O. Zebua, and N. Soedjarwanto, "Perancangan Sistem Pengaturan Suhu Kandang Ayam Berbasis Mikrokontroler," no. 1.

[3] E. Wiji, S. Budianto, and A. H. Kridalaksana, "KELEMBABAN KANDANG AYAM BOILER BERBASIS MIKROKONTROLER ATMEGA328," vol. 2, no. 2, 2017.

[4] I. W. A. Mindriawan, Zulham, Arimbawa, I. G. Pasek, and S. Wijaya, "Implementasi Internet of Things Pada Sistem Monitoring Suhu dan Kontrol Air Pada Kandang Burung Puyuh Petelur dengan Menggunakan Protokol MQTT ( Implementation of Internet of Things on Temperature Monitoring Systems and," pp. 1-8.

[5] Ardiyanto and Nurfiana, "Sistem kontrol intensitas cahaya pada kandang puyuh berbasis arduino uno," vol. 15, no. 1, pp. $1-9,2015$.

[6] A. Saleh, "Implementasi Metode Klasifikasi Naïve Bayes Dalam Memprediksi Besarnya Penggunaan Listrik Rumah Tangga," vol. 2, no. 3, pp. 207-217, 2015.

[7] D. Wu, Z. Jiang, X. Xie, and X. W. Member, "LSTM Learning with Bayesian and Gaussian Processing for Anomaly Detection in Industrial IoT," vol. 3203, no. c, 2019.

[8] D. N. Usep Tatang Suryadi, "SISTEM PENENTUAN KUALITAS PAVING BLOCK BERDASARKAN PARAMETER NUMERIK MENGGUNAKAN METODE NAÏVE BAYES Usep Tatang Suryadi *1 , Dedi Nurzaenudin \#2,” pp. 1-13, 2016.

[9] S. Jagtap, S. Rahimifard, and U. Kingdom, "Utilisation of Internet of Things to Improve Resource Efficiency of Food Supply Chains." 